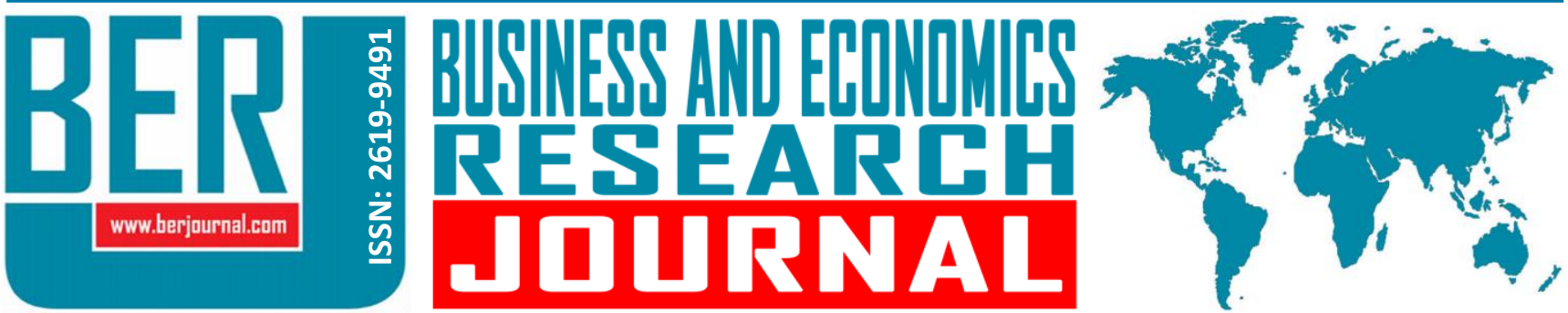 \\ Business and Economics Research Journal Vol. 12, No.1, $2021 \quad$ pp. 1-15 \\ doi: $10.20409 /$ berj.2021.307
}

\section{Is Education Compulsory for Environmental Quality? An Empirical Study on EKC and Education Nexus}

\section{Billur Engin Balin ${ }^{\mathrm{a}}$}

Abstract: Studies analyzing the environmental impacts of economic growth and considering the nexus between the stages of development remain popular since the 90s. The Environmental Kuznets Curve (EKC) hypothesis suggests that there is an inverted-Ushape relationship between per capita income and damage to the environment. Within the vast EKC literature, various variables that may have an impact on environmental pollution were included in the models. However, studies examine the effect of education on environmental quality are relatively new. In this study, the EKC hypothesis is tested in terms of per capita income and education level by using data from the period of 19982014 of 47 countries. Environmental pollution is measured by carbon dioxide per capita; income level is measured by GDP per capita, and education level is measured by the number of students enrolled in tertiary education and the share of public expenditures on education in GDP. According to the empirical findings; (i) The Environmental Kuznets Curve hypothesis is confirmed for only the number of students enrolled in tertiary education, (ii) there is a significant and negative relationship between the share of public expenditures on education in GDP and $\mathrm{CO} 2$ emissions. Therefore education can be evaluated as a powerful tool for environmental policy.
Keywords: Environmental Kuznets Curve, Education, $\mathrm{CO} 2$ emissions, Economic Growth, Panel Data

JEL: Q56, 125

\section{Introduction}

The sustainability and environmental impacts of economic growth have begun to be investigated noteworthy since the 1970s. The famous report "The Limits to Growth" (Meadows et al., 1972) was the first study to examine the sustainability of continued growth in the human ecological footprint. The central point of the report was that "the earth is finite" and growing population and demands for material wealth would lead to more industrial output and pollution. Therefore, according to the report, future growth was only possible by limiting today's growth.

Since the 1990s, theoretical and empirical studies linking the environmental impacts of economic growth to the stages of development have gained importance. The typical result of these studies is that the environment is further destroyed based on continuous economic growth in the early stages of development. Still, in the later stages of development, the situation turns opposite. The Environmental Kuznets Curves (EKC hereafter) suggests an inverted-U-shape relationship between per capita income and environmental degradation. The EKC hypothesis is based on the Nobel Prize-winning work of Simon Kuznets in 1955. In this study, Kuznets described an inverted-U-shape relationship between income distribution inequality and income per capita. 
The EKC hypothesis supports the sustainable development view by exposing that economic growth is not a constraint for environmental degradation. The hypothesis has been discussed in many theoretical and empirical studies. However, three pioneering studies have been stood out amongst others: Grossman and Krueger $(1991,1995)$, Shafik and Badyopadhyay (1992), and Panayotou (1993) found an inverted-U-shape relationship between different pollutants and income per capita. Grossman and Krueger (1995) proposed that economic growth influenced environmental quality over three different channels. "Scale effect" points out the increasing economic activity results with the expanding use of resources and land clearance; this will raise the waste both in terms of quantity and toxicity. "Composition effect" involves the structural change in economy with the increasing production such as movement from manufacturing to the service sector or hightech industries; thus, it can be expected that this has positive environmental effects. Finally, "technological effect" refers to the increasing public demand for environmental quality as per capita income goes up. Increasing public demand for environmental quality leads to both an increase in government protection of the environment and some technological improvements over time make production per unit of output cleaner. Accordingly, the EKC hypothesis propounds that in early stages of the development scale effect is dominant, thus when per capita income increases the pollution per capita also increases. Contrarily, owing to the composition and technological effects are being dominant over scale effect after a certain level of income per capita, this trend will become reversed.

After these seminal works, numerous studies have been done within almost three decades to test the existence of EKC curve with various econometric techniques. Different variables that may influence environmental degradation have been included to the models such as trade openness, foreign direct investment inflows, financial liberalization, renewable and nonrenewable energy consumption, urbanization, innovation, agricultural production, democracy level, education level and so on. ${ }^{1}$

EKC is very popular in the environmental economics literature; still, there are some criticisms against it. Firstly EKC is modelled for only some selected indicators of environmental degradation, which means that some of the pollutants are not considered according to the data availability. Another point is the difference between the growth path of developing and developed countries was missed in many studies and assumed developing countries should follow the same path with developed countries. Additionally, many EKC studies focus on the production level and neglect the effect of consumption patterns on environmental degradation. ${ }^{2}$

Figure 1. Possible Transmission Channels from Education to Environmental Quality

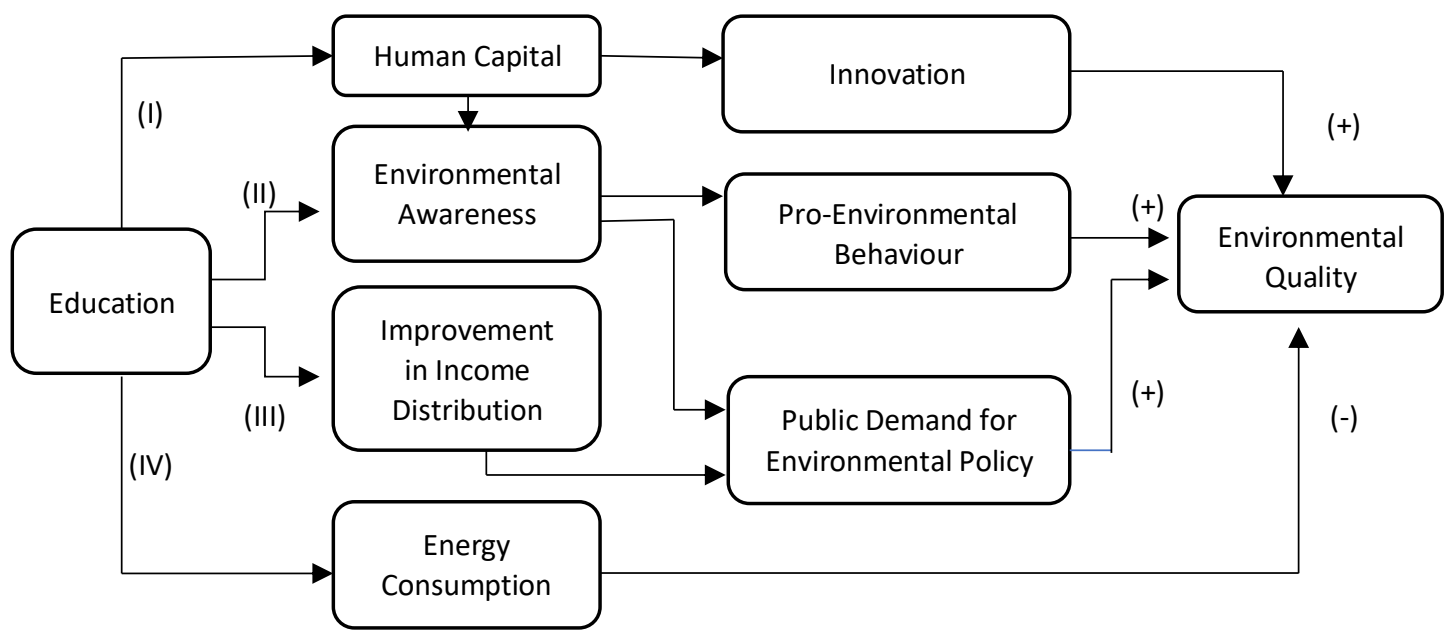

Figure 1 represents the possible transmission channels from education to environmental quality. Four main channels may be proposed for this transmission:

(I) Increasing the level of education contributes to improving human capital. Accordingly, green innovations can be adapted easier by the human capital equipped with the specific knowledge 
and skills to integrate cleaner technologies. Moreover, the increasing level of education improves the quality of the population and may affect environmental awareness directly.

(II) With increasing education level, public awareness about environmental issues raises. Increasing environmental awareness is expected to promote pro-environmental behaviour of the households. Pro-environmental behaviour can be defined as the sum of as all possible actions aimed at avoiding harm to and/or safeguarding the environment, either performed in public (e.g., participation in environmental movements) or private domains (Balunde et al., 2019: 2). Additionally, increasing environmental awareness supports the public demand for stronger environmental regulations from the authorities.

(III) Including Simon Kuznets' mentioned study (1955), there are numerous studies that proves human capital, accordingly education, is one of the most important determinants of income inequality. Therefore, the improvement of education level can reduce the detrimental effects of the differences in income distribution and enhance environmental quality.

(IV) Finally, increasing education level may change the consumption patterns from primary consumption towards energy-intensive consumption. Mostly fixed capital and infrastructure investments, urbanization and rising transportation demand as the main determinants of the energy demand are expected to raise the level of pollution.

The idea of there may be an inverted-U-shape relationship between environmental degradation and education is based on the existence of two opposite effects: While human capital (I), environmental awareness (II), and income distribution (III) channels affect the environmental quality positively (i.e. decreases the environmental degradation); energy consumption channel works in the opposite direction. Hence, the model used in this study argues the first three channels dominate the energy-intensive consumption channel after a specific threshold education level.

Thus far, studies focused on the non-linear relationship between education and environmental degradation followed two paths: Balaguer and Cantavela (2018) and Umaroh (2019) used time-series data of Australia and Indonesia, respectively. On the other hand, Lotz and Morales (2017) and Zafar et al. (2020) examined panel data models for the countries in a specific development level or a particular region. The common point of these studies was they widened the time dimension by limiting the country dimension. This study aims to contribute to the related literature by using panel data for 47 countries and 17 years (19982014). Differently than the previous literature, this study intends to provide a broader view of the non-linear relationship by expanding the countries included and sacrificing the time dimension according to the data availability. By covering more countries in different development and education levels, this study is intended to search inverted-U-shaped relationship for education and income on a global scale. Besides checking the inverted-u-shape relationship between education level and environmental degradation, it is also checked the standard EKC hypothesis.

The rest of this paper is organized as follows. Section 2 presents the discussion of relevant literature. Section 3 covers the data and the model. Section 4 illustrates the empirical analysis and discusses the findings. Section 5 is concluding remarks.

\section{Literature}

Although there are numerous studies about EKC and related variables since the 90s, studies examine the effect of education on environmental quality are relatively new. Some of these studies try to investigate the relationship between formal education and pro-environmental behaviour by using surveys within the micro-based approach. On the other side, most of the studies approach the topic in macro-basis: Human capital/education and income are assumed to be highly correlated; therefore, education might have an impact on environmental quality.

Initial studies that considered education as an explanatory variable within the EKC framework did not have a consensus about the direction of the relationship. Gangadharan and Valenzuela (2001) examined the 
link between the health indicators and the environmental variables for a cross-section of countries. They established a two-stage model for health and the environment. Education proxied by gross enrollment ratio was used as a regressor in their environment model. They observed a positive coefficient for the education variable for all pollutants, so higher levels of education aggravate, rather than improve, environmental conditions. Hill and Magnani (2002) stated that the estimated EKC relationship is highly sensitive to the choice of pollutant, the sample of countries and sample of periods. This lack of stability was explained with omitted variables problem, and the average number of years of schooling in the population aged 25 as a proxy of education was included in the model as an explanatory variable. They found the education coefficient is positive, which implies that other things equal, higher education levels increase pollution. Ehrhardt-Martinez et al. (2002) studied on ecological modernization theory and international political economy arguments to examine the sources of EKC for deforestation. They used the education, measured by the percentage of the population that had attended school at the secondary level, to capture political modernization. Their results showed that there is significant potential for regenerating forests trough increased level of education. Bimonte (2002) emphasized that besides economic growth, income distribution, education and information accessibility may play a fundamental role in determining environmental quality. He used a sample of countries being at the last stage of development. He claimed that change in income inequality, information access and education act as a shifter of the EKC in the same direction.

Micro-based studies focus on the impact of education on pro-environmental behaviour of the households. Büchs and Schnepf (2013) examined how household characteristics differ in their association with home energy, transport and household $\mathrm{CO}_{2}$ emissions by using a representative UK expenditure survey. They found that high education was positively associated with almost all areas of emissions, and particularly with transport emissions. Muttarak and Chankrajang (2015) investigated demographic differentials in levels of concern about climate change and climate-relevant behaviours by using "Opinions about the Environment and Global Warming Survey" made in Thailand. Their findings suggested that education increases both the level of concern about climate change and the capacity to carry out climate-friendly actions. Meyer (2015) implemented a regression discontinuity design to estimate the increase in educational attainment due to changes in compulsory education laws in 20th century Europe. He found a positive local average treatment effect for seven of the eight pro-environmental behaviours. His results supported the notion that education causes individuals to be more concerned with social welfare and to behave in a more environmentally friendly manner accordingly. Chankrajang and Muttarak (2017) studied whether formal education encourages pro-environmental behaviours using nationally representative surveys on environmental issues in Thailand. They found that more years of schooling lead to a higher probability of taking knowledge-based environmentally friendly actions. However, they did not find a significant impact of formal education on concern about global warming. Salahodjaev (2018) explored the effect of cognitive abilities on climate change awareness using data from 119 countries. Climate change awareness data was collected from "Gallup World Poll", and the national average of cognitive abilities (includes nationally administered IQ tests, school assessment tests and adult literacy studies) constructed by Rindermann (2007) was used. Their results indicated that cognitive abilities are significantly linked with a nation's level of climate change awareness in the cross-country sample. Ponce et al. (2019) examined the green returns of labour income and human capital in Ecuador. Their results showed that human capital (proxied by average years of schooling) have a positive effect on the environmental friendly behaviour of households in this country.

Macro-based studies, on the other hand, emphasize the effect of education level on environmental quality. Although $\mathrm{CO}_{2}$ is the most common variable to measure the environmental quality, the other greenhouse gases (such as methane and NOX), some air pollutants (such as $\mathrm{SO}_{2}$ ) and ecological footprint were also used in the literature. Depending upon the data availability, education level is generally measured by enrollment ratios to the primary/secondary/tertiary schools and Human Capital Index of Penn World Table based on the average years of schooling and assumed rate of return to education.

Some of the macro-based studies examined the relationship between economic growth and environmental quality in linear form (not in the EKC framework) and they added education level as an explanatory variable. Managi and Jena (2008) analyzed the determinants of environmental productivity in 
Indian regions and found a combined effect of income on environmental productivity is negative. Education index is used as an independent variable to analyze the determinants of environmental productivity. They found a positive coefficient for the education index, though the magnitude of this coefficient is small. Therefore, Indian regions with a higher level of education seem to have experienced a lesser amount of environmental degradation. Uddin (2014) tested the relationship among education (proxied by education expenditures), environmental pollution (proxied by $\mathrm{CO}_{2}$ ) and economic growth in Bangladesh and found a strong positive relationship among environmental pollution, education expenditure and economic growth. Ekperiware et al. (2017) examined the coordinating role of human capital among the three pillars of sustainable development in Nigeria. Their analyses showed that environmental degradation $\left(\mathrm{CO}_{2}\right.$ emission) was negatively affected by increasing human capital formation (government expenditures on education and health) but increased with economic growth. Bano et al. (2018) studied the long- and short-term effects of human capital (proxied by secondary school enrolment and human capital index) on carbon emissions in Pakistan and found a significant long-term relationship between human capital and carbon emissions. Katircioglu et al. (2020) estimated the effects of higher education development on climate change through energy consumption in Turkish Republic of Northern Cyprus. They found a positive and significant impact of higher education growth on climate change via energy consumption and concluded that educational development in Northern Cyprus is a long-term contributor to the energy sector and, therefore, climate change. Eyuboglu and Uzar (2020) tested the trade-off between higher education and $\mathrm{CO}_{2}$ in Turkey. Their results denoted an increase in higher education (proxied by the enrollment of students in higher education) negatively affects $\mathrm{CO}_{2}$. In other words, they found that developments in higher education can be an essential catalyst in the reduction of $\mathrm{CO}_{2}$ in Turkey.

Another group of macro-based studies checked the existence of EKC and extended the hypothesis with a single educational variable. Dutt (2009) explored the roles of governance, political institutions, socioeconomic conditions, and education in influencing the EKC. Their results supported the existence of EKC for $\mathrm{CO}_{2}$. Still, the education indicators (average years of schooling in the adult population and expenditure on education) was found statistically insignificant in the two of three models. Nevertheless, he claimed that the education expenditures could serve as a proxy for income and shift downward the EKC with regard to the high degree of correlation between education expenditure and income. Sapkota and Bastola (2017) tested the validity of the Pollution Haven Hypothesis and the EKC hypothesis for 14 Latin American countries. They used educational attainment (average years of schooling of the population aged 15 and above) as a proxy of human capital stock. Their results suggested that the impact of education on pollution (namely $\mathrm{CO}_{2}$ ) emission is different across income groups: pollution was found negatively correlated with human capital in lowincome countries and positively correlated in high-income countries. Williamson (2017) estimated $\mathrm{CO}_{2}$ and methane emissions of 181 countries in 2012 by using GDP per capita, education (mean years of schooling for persons 25 years and older) and government regime as control variables. It was tested whether education levels would shift the EKC downwards and found that substantial evidence could not be provided to prove the validity of the hypothesis regarding the levels of education. Ulucak and Bilgili (2018) reinvestigated EKC hypothesis for ecological footprint and checked the possible effects of trade openness, human capital and biocapacity. Human capital is proxied by the human capital index. Their results confirmed the EKC and represented a negative relationship between environmental degradation and human capital index level. Chen et al. (2019) examined a panel data covering more than 60 countries to investigate the impacts of environmental awareness on environmental performance. They tested a two-staged model: Socio-economic indicators, including education (proxied by tertiary education enrollment rate), was used as a control variable in the public environmental awareness model and found a positive relationship. Then the relationship between environmental awareness and environmental quality was checked and found that an increase in environmental awareness creates a beneficial effect on regional environmental quality by flattening the EKC and shifting it to the left. Gui et al. (2019) utilized panel data of 285 Chinese cities to explore the spatial dependence of the municipal solid waste. They found that education level (proxied by the number of regular institutions of higher education) are slightly negatively correlated with municipal solid waste generation, and GDP per capita has a mutual improvement relationship with municipal solid waste generation instead of inverted U-shape as predicted by EKC. Pata and Caglar (2020) empirically examined the ecological outcomes 
of income, human capital, globalization, renewable energy consumption, and trade openness for China within the framework of the EKC hypothesis. Their findings revealed that there is U-shaped (instead of inverted-U shape) relationship between GDP per capita and $\mathrm{CO}_{2}$ and ecological footprint. They also found that increasing human capital (proxied by human capital index) reduces the ecological footprint in the longterm. On the contrary of Pata and Caglar (2020), Sarkodie et al. (2020) investigated the impact of energy utilization, human capital, trade, income level and natural resource exploitation on $\mathrm{CO}_{2}$ emissions and ecological footprint in China. The EKC hypothesis is validated in both $\mathrm{CO}_{2}$ and ecological footprint functions. Moreover, their empirical results showed that increasing human capital (proxied by human capital index) is conducive for the escalation of emissions and environmental degradation.

Two studies should be emphasized here, which differ from the studies as mentioned above. Although they included educational variables to their models in a linear form; they both used two different educational levels to check the inverted-U-shape relationship between education and environmental degradation implicitly. Aytun (2014) analyzed ten emerging countries' data to investigate the effect of different education levels on $\mathrm{CO}_{2}$ emissions. His results supported the EKC hypothesis for the GDP. He also proposed an "implicit" EKC for the $\mathrm{CO}_{2}$ and two different education levels and found that $\mathrm{CO}_{2}$ emissions are positively related to the secondary education level while negatively associated with the tertiary education level. Similarly, Mahalik et al. (2021) evaluated the role of primary and secondary education levels in curbing carbon emissions for selected BRICS countries. Their study revealed that primary education contributes to rising carbon emissions, whereas secondary education contributes to improving environmental quality by reducing carbon emissions.

Finally, four studies were detected that the education variable was included in the model in nonlinear form and checked the inverted-u-shape relationship between environmental degradation and education explicitly. Lotz and Morales (2017) analyzed the causal relationship between primary energy consumption and education for a group of developed and developing countries as well as the global panel. Education was measured with the total enrolment in secondary education and to check the existence of a non-linear relationship between energy consumption and education, squared of education is included in the model. For the global panel, a non-linear relationship between energy consumption and education was detected, which follows a similar path to energy and environmental Kuznets curve. Nonetheless, they found that higher education levels in developing countries increase energy consumption while energy consumption falls with higher education levels in developed countries. Balaguer and Cantavela (2018) hypothesized that education might directly affect environmental quality by worsening it at early stages and improving it once education expands from its certain level and extended EKC hypothesis by asserting an inverted-u-shape relationship between education and environmental quality. The hypothesis was applied to Australian data for a substantial period (1950-2014) and found that expansion in education rate (proxied by tertiary school enrollment) has increasingly compensated the rise of per capita $\mathrm{CO}_{2}$ emissions stemming from the economic growth. Moreover, only in recent years, both per capita income and education expansion have been proved to reduce emissions. By following the footsteps of Balaguer and Cantavela (2018), Umaroh (2019) analyzed whether education (proxied by tertiary school enrolment) has a role in energy use in Indonesia. His results confirmed not only the "ordinary" EKC relationship between GDP and $\mathrm{CO}_{2}$, but he also found evidence that education initially increases $\mathrm{CO}_{2}$ emissions and after the critical level of education $\mathrm{CO}_{2}$ emissions reduces in the short run. Zafar et al. (2020) investigated the effect of foreign direct investment and education on environmental quality $\left(\mathrm{CO}_{2}\right)$ for Asian countries. They developed a linear and a quadratic model for foreign direct investment, GDP and education (proxied by gross secondary school enrollment). They found education positively affects $\mathrm{CO}_{2}$ emissions in the linear form, while negatively affects in the non-linear form. Therefore they proposed an inverted-U-shaped link between education and carbon emissions which can be referred to as an "Education Kuznets Curve". 


\section{Data and Model}

The data was collected from the World Development Indicators (2018) compiled by the World Bank for 47 countries between 1998 and $2014^{3}$. Study period and the country sample is limited by data availability. Twenty-seven of the sample counties are in the very high human development, eleven are in the high human development, and nine are in the medium and low human development classification in the Human Development Index within the corresponding period.

It is focused on carbon dioxide $\left(\mathrm{CO}_{2}\right)$ emissions per capita as a proxy of environmental degradation. $\mathrm{CO}_{2}$ is assumed as the most critical global pollutant with the share of about $80 \%$ within all greenhouse gases emitted, causing global warming. For the independent variables, GDP per capita in the year 2010, constant prices was used. In line with the related literature, tertiary education (gross) school enrollment ratio is assumed as the primary proxy of education level. Gross enrollment ratio is defined as the ratio of total enrollment, regardless of age, to the population of the age group that officially corresponds to the level of education shown. It indicates the capacity of the education system. Government expenditures on education (as a share of GDP) were also adopted as supporting independent variable for education dimension of the study. General government expenditure on education (as a percentage of GDP) is a useful tool to compare education expenditure between countries and/or overtime concerning the size of their economy. A high percentage of GDP represents a high priority for education and capacity of raising revenues for public spending (WDI, 2018).

The descriptive statistics on variables are summarized in Table 1 . The number of valid observations is 799, and the average emission volume of $\mathrm{CO}_{2}$ is 6.28 metric tons. The value of $\mathrm{CO}_{2}$ per capita ranges from 0.07 metric ton in Madagascar (2002) to 67.11 metric tons in Qatar (2001). Regarding the GDP per capita, Norway is the wealthiest country (in 2007, \$91617.28) while Madagascar is the poorest one (in 2002, \$374.49). In respect to tertiary education school enrollment ratio, Madagascar has the lowest rate with 2.03 (2001) whereas Korea has the highest at 104.21 (2009). Besides, Moldova has the highest government expenditure on education in 2009 with 9.51\% of its GDP while Lao PDR has the lowest in 2000 with 1.50\%.

Table 1. Descriptive Statistics

\begin{tabular}{llcccc}
\hline Variable & Description & Min. & Max. & Mean & Std. Dev. \\
\hline $\mathrm{CO}_{2}$ & Carbon dioxide emissions per capita, metric tons & 0.07 & 67.11 & 6.28 & 7.80 \\
y & GDP per capita, constant, 2010 US\$ & 374.49 & 91617.28 & 20768.26 & 21661.74 \\
ed & Tertiary education school enrollment ratio, \% of gross & 2.03 & 104.21 & 47.33 & 23.49 \\
gov & Government expenditure on education, \% of GDP & 1.50 & 9.51 & 4.82 & 1.38 \\
\hline
\end{tabular}

Fig. 2 presents the plots of GDP per capita, tertiary education school enrolment ratio and government expenditure on education versus per capita $\mathrm{CO}_{2}$ emissions. As a visual inspection, an inverted-U-shape relationship between GDP and $\mathrm{CO}_{2}$ emissions appears as expected. While graphical representation between education level and $\mathrm{CO}_{2}$ emissions was indicating a positive relationship, it seems hard to predict the relationship between government expenditures on education and $\mathrm{CO}_{2}$ emissions from the scatterplot.

In this study, it is implemented a panel data model since panel data has some advantages over time series and cross-section data. In contrary to time series and cross-sectional data, panel data (i) control individual heterogeneity, (ii) give more informative data, more variability, less collinearity among the variables, more degrees of freedom and more efficiency, (iii) are better able to study the dynamics of adjustment (iv) are better able to identify and measure effects that are simply not detectable in pure crosssection or pure time-series data. (v) allow us to construct and test more complicated behavioural models than pure cross-section or time-series data. (vi) Biases resulting from aggregation over firms or individuals may be reduced or eliminated by micro panel data. (vii) Macro panel data have a more extended time series and unlike the problem of nonstandard distributions typical of unit roots tests in the time-series analysis (Baltagi, 2005). Karlsson and Löthgren (2000) and Levin et al. (2002) stated that panel unit root test would be 
sufficiently robust for panels of moderate size $(10<\mathrm{N}<250$ and $25<\mathrm{T}<250)$. However, for small $\mathrm{T}$, panel unit root tests have low power, and there is the potential risk of concluding that the whole panel is nonstationary even when there is a large proportion of stationary series in the panel. Similarly, standard panel cointegration tests are known to have low power, especially for short T and short span of data (Baltagi, 2005). Therefore, the usual panel regression analysis has chosen since the time dimension of this study is relatively short $(T=17)$.

Figure 2. Scatterplots of Variables

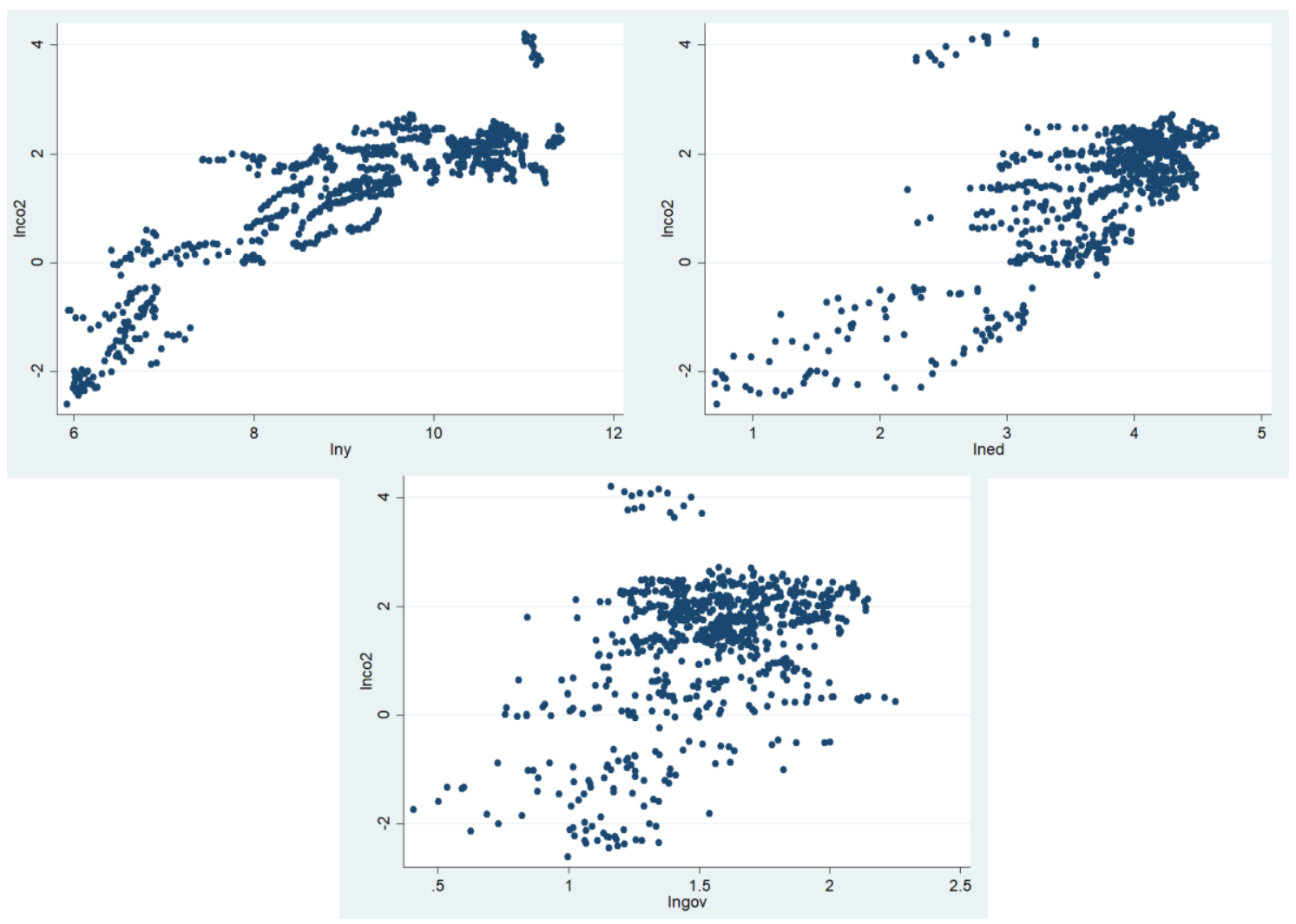

The vast literature on the EKC hypothesis generally assumes that environmental degradation is explained with the quadratic function of income. Since the study is interested in an EKC related to $\mathrm{CO}_{2}$ emissions in both income and education dimensions, the following model will be considered:

$$
\operatorname{lnCO}_{i t}=\beta_{0}+\beta_{1} \ln y_{i t}+\beta_{2} \ln y_{i t}^{2}+\beta_{3} \operatorname{lned}_{i t}+\beta_{4} \operatorname{lned}_{i t}^{2}+\beta_{5} \operatorname{lngov}_{i t}+\mu_{i}+u_{i t}
$$

where $i=1,2, \ldots . N$ for each country in the panel and $t=1,2, \ldots \ldots . ., T$ refers to the period. $\mathrm{CO}_{\text {it }}$ refers to the carbon dioxide emissions per capita, $y_{i t}$ denotes real GDP per capita, ed $d_{i t}$ indicates the tertiary education school enrollment ratio, govit refers to government expenditures on education. All variables are transformed into natural logarithms. $\beta_{0}$ stands for the specific country-pair effects and allows controlling for all omitted variables that are cross-sectionally specific but remain constant over time. $\mu_{i}$ denotes the unobservable country-specific effect, and $u_{i t}$ means the remainder disturbance. $\beta_{1}$ and $\beta_{2}$ are the coefficients of GDP per capita and squared GDP per capita. Under the EKC hypothesis, the signs are expected to be positive and negative, respectively. Moreover, if significant parameters satisfy $\beta_{3}>0$ and $\beta_{4}<0$, there exist an inverted-Ushape relationship between education and $\mathrm{CO}_{2}$ emissions. The government expenditures on education are defined as a share of GDP means it is not only an educational variable but also sensitive to the changes in GDP. That is why, in this study, it is assumed as an implicit and supportive indicator for education and added to the model in linear form. The coefficient of government expenditures on education, $\beta_{5}$, may be positive or negative. 
The extended relationship (where $\beta_{1}>0, \beta_{2}<0, \beta_{3}>0$, and $\beta_{4}<0$ ) can be described as a paraboloid as in Figure $3 a$. The lines are referred to as isoquants and represent the different levels of emissions. On the logarithmic scale, turning points (where $\mathrm{CO}_{2}$ is maximized) for income and education level can be calculated as $y^{*}=$ $\left(-\frac{\beta_{1}}{2 \beta_{2}}\right)$ and $e d^{*}=\left(-\frac{\beta_{3}}{2 \beta_{4}}\right)$. $\operatorname{Exp}\left(\mathrm{y}^{*}\right)$ and $\operatorname{Exp}\left(\mathrm{ed}^{*}\right)$ represent the value of the turning points.

Figure 3. $\mathrm{CO}_{2}$ Emissions as a Quadratic Function of Income and Education

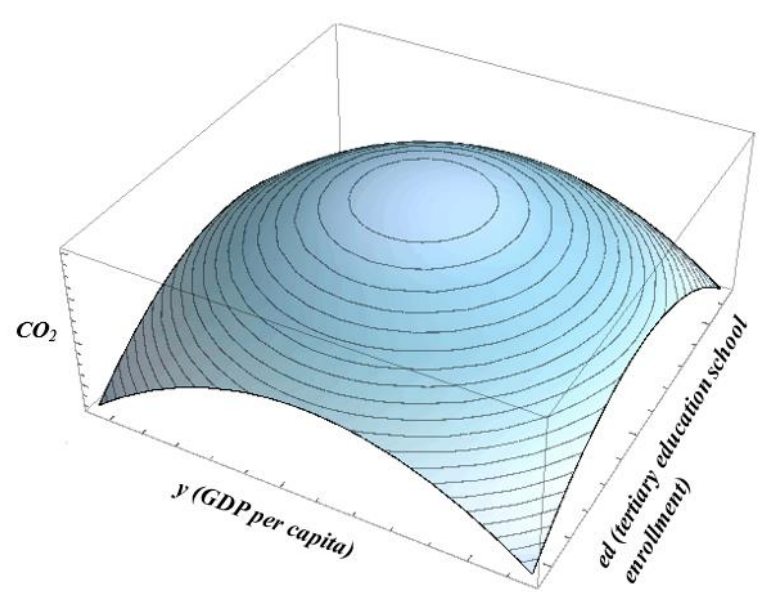

(a)

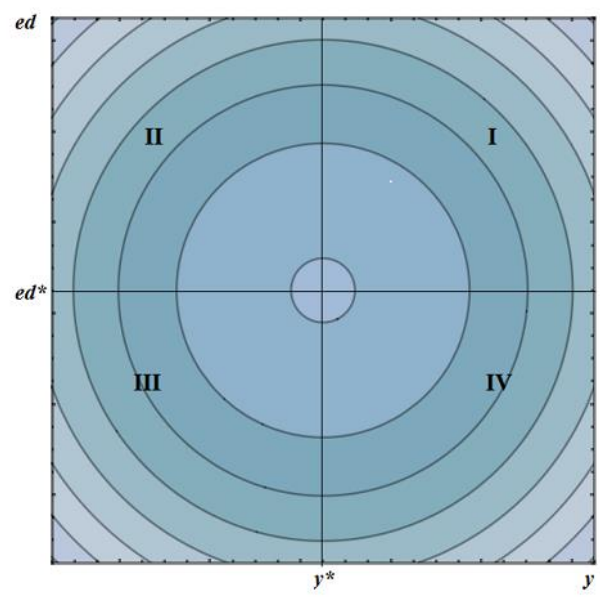

(b)

The trade-off between income and education for a certain level of $\mathrm{CO}_{2}$ emission is represented by the slope of the isoquants shown in Figure $3 \mathrm{~b}$. It can be called the marginal rate of substitution (MRS) of income for education. We can divide the two-dimensional contour graph into quadrants according to the slope of the isoquants. Depending on the quadrant where a country is located, the appropriate strategy can be determined to decrease the $\mathrm{CO}_{2}$ emissions.

Table 2. Appropriate Strategy to Decline $\mathrm{CO}_{2}$ emissions

\begin{tabular}{|c|c|c|c|c|}
\hline \multicolumn{2}{|c|}{ Location } & \multicolumn{2}{|c|}{ Partial Derivatives } & Appropriate strategy to decline $\mathrm{CO}_{2}$ emissions \\
\hline Quadrant I & $\begin{array}{c}y>y^{*} \\
e d>e^{*}\end{array}$ & $\begin{array}{l}\frac{\partial \mathrm{CO}_{2}}{\partial y}<0 \\
\mathrm{y} \uparrow \mathrm{CO}_{2} \downarrow\end{array}$ & $\begin{array}{l}\frac{\partial C \mathrm{O}_{2}}{\partial e d}<0 \\
\text { ed } \uparrow \mathrm{CO}_{2} \downarrow\end{array}$ & $\begin{array}{l}\text { Economic growth and/or increase in the level of } \\
\text { education will help to tackle emission levels. } \\
\text { - Even if one of the education level or income } \\
\text { decreases, it is possible to decline the emission } \\
\text { level by increasing the other one more than the } \\
\text { MRS of income for education. }\end{array}$ \\
\hline Quadrant II & $\begin{array}{c}\mathrm{y}<\mathrm{y}^{*} \\
\mathrm{ed}>\mathrm{ed}^{*}\end{array}$ & $\begin{array}{l}\frac{\partial C O_{2}}{\partial y}>0 \\
\mathrm{y} \downarrow \mathrm{CO}_{2} \downarrow\end{array}$ & $\begin{array}{l}\frac{\partial C \mathrm{O}_{2}}{\partial e d}<0 \\
\text { ed } \uparrow \mathrm{CO}_{2} \downarrow\end{array}$ & $\begin{array}{l}\text { - A decrease in per capita income and/or an } \\
\text { improvement in the education level are expected } \\
\text { to decline emission levels. } \\
\text { - If a positive growth rate emerges, improvement in } \\
\text { education level must dominate the economic } \\
\text { growth to decline the emissions. }\end{array}$ \\
\hline Quadrant III & $\begin{array}{c}\mathrm{y}<\mathrm{y}^{*} \\
\text { ed }<\mathrm{ed}^{*}\end{array}$ & $\begin{array}{l}\frac{\partial C \mathrm{O}_{2}}{\partial y}>0 \\
\mathrm{y} \downarrow \mathrm{CO}_{2} \downarrow\end{array}$ & $\begin{array}{l}\frac{\partial C O_{2}}{\partial e d}>0 \\
\text { ed } \downarrow \mathrm{CO}_{2} \downarrow\end{array}$ & $\begin{array}{l}\text { - Negative growth and/or reduce educational level } \\
\text { will abate the emissions. } \\
\text { - If one of the variables increases, the other variable } \\
\text { must decrease more than MRS to struggle with the } \\
\text { emission level. }\end{array}$ \\
\hline $\begin{array}{l}\text { Quadrant } \\
\text { IV }\end{array}$ & $\begin{array}{c}\mathrm{y}>\mathrm{y}^{*} \\
\text { ed }<\mathrm{ed}^{*}\end{array}$ & $\begin{array}{l}\frac{\partial C O_{2}}{\partial y}<0 \\
\mathrm{y} \uparrow \mathrm{CO}_{2} \downarrow\end{array}$ & $\begin{array}{l}\frac{\partial \mathrm{CO}_{2}}{\partial e d}>0 \\
\text { ed } \downarrow \mathrm{CO}_{2} \downarrow\end{array}$ & $\begin{array}{l}\text { - Economic growth and/or decrease in the level of } \\
\text { education will decrease per capita emissions. } \\
\text { - If education level improves, growth rate must } \\
\text { exceed MRS to decline the emissions. }\end{array}$ \\
\hline
\end{tabular}




\section{Empirical Analysis}

At the first stage of the analysis, it is focused on choosing a valid model. Baltagi (2005) states that the random-effects model (REM) is an appropriate specification if the observations are drawn randomly from a large population while the fixed effects model (FEM) is a proper specification if the observations focus on a specific set of samples under similar conditions. Hence, the Hausman specification test was applied to choose the valid model, and the data support the FEM.

Thereafter the model was tested for heteroscedasticity, cross-sectional dependence and serial correlation. Modified Wald test for groupwise heteroscedasticity demonstrated the rejection of the null hypothesis of homoscedasticity. Pesaran's test of cross-sectional independence indicated that the null hypothesis was rejected at the $1 \%$ significance level. Both Baltagi-Wu local best invariant (LBI) test and Durbin-Watson test stated the existence of serial correlation. Test results are given in the Appendix. Finally, to fix these three issues, -heteroscedasticity, cross-sectional dependence and serial correlation- DriscollKraay estimator was adopted. The results presented in Table 3 are the robust coefficients that are adjusted by Driscoll-Kraay estimator.

Table3. Panel-data Regression Results

\begin{tabular}{|c|c|c|}
\hline $\mathrm{InCO}_{2}$ & Coefficient & $\begin{array}{c}\text { Driscol/Kraay } \\
\text { Standard Errors }\end{array}$ \\
\hline $\ln y$ & $1.292246^{*}$ & 0.271798 \\
\hline $\ln y^{2}$ & $-0.050840^{*}$ & 0.015644 \\
\hline lned & $0.672137^{*}$ & 0.131514 \\
\hline $\operatorname{lne} d^{2}$ & $-0.106595^{*}$ & 0.018693 \\
\hline lngov & $-0.080842^{* *}$ & 0.040232 \\
\hline constant & $-7.016044^{*}$ & 1.238132 \\
\hline within R-squared & 0.2829 & \\
\hline$F(5,46)$ & 41.6700 & \\
\hline Prob $>F$ & 0.0000 & \\
\hline turning point for $y$ & 330702 & \\
\hline turning point for ed & 23.40 & \\
\hline
\end{tabular}

The model is found significant by F-test. $R^{2}$ of the model is 0.2829 , which represents that about $30 \%$ of the change in the per capita $\mathrm{CO}_{2}$ emission is explained by the independent variables used in the model. All of the estimated coefficients are found statistically significant.

The signs of the significant coefficients for GDP per capita and the square of GDP per capita are as expected, positive and negative, respectively. However, the turning point of income for the inverted-U curve is estimated to be $\$ 330702$ (in constant 2010 US\$), which is considerably high. The maximum GDP per capita in the sample is 91617 (Norway in 2007). Moreover, when the WDI (2018) dataset searched, none of the countries reached this level of GDP per capita yet. Dutt (2009) stated that if the turning point calculated was outside the range of the dataset, it means that the data displayed an inverted-U-shape, however, the decreasing part of the trend was not yet observable within the given data. Lind and Mehlum (2010) extended this explanation and stated that in addition to negative sign and the significance of the second derivative, the estimated extremum point must have been within the data range to make statistical inferences of the presence of an inverted-U-shape. The calculated turning point in this study is not only out of the sample but also is an unreachable amount in the near future. Therefore EKC hypothesis cannot be confirmed for GDP per capita within the sample data. 
The estimated coefficients of education level and the square of education level are positive and negative, respectively. Therefore the data confirms the inverted-U-shape relationship between education level and $\mathrm{CO}_{2}$ emissions. The turning point of education level is estimated at $23.40 \% .77 \%$ of the valid observations in the sample (614 observations out of the 799) are above this threshold level. In other words, most of the sample countries (42 out of 47 ) are in the decreasing part of the inverted-U-shape graph. Hence, increasing level of education affects the environmental quality positively by declining the per capita $\mathrm{CO}_{2}$ emissions.

The estimated coefficient of the government expenditure for education is found significant and negative indicating the beneficial impact of government expenditure for education to the environmental quality: $1 \%$ increase in the government expenditure to education (as a share of GDP) causes to $0.08 \%$ decrease in $\mathrm{CO}_{2}$ emission per capita. Although the value of the coefficient is relatively low, it supports the findings for the education level.

\section{Concluding Remarks}

In this study, the relationship between environmental pollution, income and education level was examined by using annual country-level data from 1998 to 2014 for 47 countries. The validity of inverted-Ushape relationship was checked for not only between pollution and income but also between pollution and education. Inverted-U-shape relationship between income and pollution was studied many times under the EKC hypothesis. Nevertheless, studies that consider the education level as an explanatory variable for pollution is quite new. This is one of the precursor studies that set up a quadratic model to test the invertedU-shape relationship between pollution and education.

The results confirmed that the EKC hypothesis is valid for only the education level within the sample period and countries. Education level was represented by two variables: tertiary education school enrollment ratio and government expenditures on education. A significant inverted-U-shape relationship was found between pollution and tertiary education school enrollment ratio. Test results also suggest that there is a meaningful negative relationship between government expenditures for education and pollution level. The threshold level for education indicates that 42 countries (out of 47 ) are located in the decreasing part of the inverted-U-shape graph. The negative sign of government expenditures on education also supports this result.

For per capita income, although the significant coefficients were found with expected signs, the turning point is considerably high; none of the countries within the sample reaches that amount. Furthermore, the threshold level calculated is unreachable in the near future. Hence, an important result of this study is to reject the validity of the EKC hypothesis for income.

The outcomes of this study suggest that education has a greater potential effect on environmental quality than economic growth. According to the model results, the sample is located in quadrant II explained in Table 2. Since the turning point is found unreachable, it is evident that an increase in GDP per capita cannot be a suitable strategy to decline the pollution level. However, the appropriate policy would be to increase the education level to improve environmental quality. This study proves that policymakers must not ignore the significant relationship between environmental quality and education.

Education has a vital role in achieving a sustainable environment by improving human capital and allowing the country to address problems innovatively. With the proper education policies, to provide the knowledge and skills that will produce cleaner technologies and to increase public awareness would be the attainable goals for better environmental quality.

Future studies can improve the quadratic model of education for different environmental indicators such as local air pollutants or more complex measure like the ecological footprint. Additionally, to integrate aggregate pro-environmental behaviour of the households to the macro-based models will enlarge the discussion in the issue. 


\section{Disclosure Statements}

1. The author of this article confirms that her work complies with the principles of research and publication ethics.

2. No potential conflict of interest was reported by the author.

3. This article was screened for potential plagiarism using a plagiarism screening program.

\section{Acknowledgements}

A shorter version of this paper was initially presented at the International Symposium on Economics, Finance and Econometrics (ISEFE 2018), 6-7 December 2018, Bandirma. I profoundly acknowledge the contributions of the conference participants. I am entirely responsible for all errors.

\section{End Notes}

1. For an extended and up to date literature survey on EKC, please see Shahbaz and Sinha (2019).

2. For detailed information please see Kaika and Zervas (2013), Ulucak and Bilgili (2018) and Gill et al. (2018).

3. The countries in the sample are listed in the Appendix.

\section{References}

Aytun, C. (2014). Gelişen ekonomilerde karbondioksit emisyonu, ekonomik büyüme ve eğitim arasindaki ilişki: Panel veri analizi. The Journal of Academic Social Science Studies, 27, 349-362.

Balaguer, J., \& Cantavella, M. (2018). The role of education in the Environmental Kuznets Curve. Evidence from Australian Data. Energy Economics, 70, 289-296.

Baltagi, B. H. (2005). Econometric analysis of panel data (3rd ed.). West Sussex: John Wiley and Sons.

Balunde, A., Perlaviciute, G., \& Steg, L. (2019). The relationship between people's environmental considerations and pro-environmental behavior in Lithuania. Frontiers in Psychology, 10, 2319.

Bano, S., Zhao, Y., Ahmad, A., Wang, S., \& Liu, Y. (2018). Identifying the impacts of human capital on carbon emissions in Pakistan. Journal of Cleaner Production, 183, 1082-1092.

Bimonte, S. (2002). Information access, income distribution, and the Environmental Kuznets Curve. Ecological Economics, 41, 145-156.

Büchs, M., \& Schnepf, S. V. (2013). Who emits most? Associations between socio-economic factors and UK households' home energy, transport, indirect and total $\mathrm{CO}_{2}$ emissions. Ecological Economics, 90, 114-123.

Chankrajang, T., \& Muttarak, E. (2017). Green returns to education: Does schooling contribute to pro-environmental behaviours? Evidence from Thailand. Ecological Economics, 131, 434-448.

Chen, X., Huang, B., \& Lin, C. (2019). Environmental awareness and environmental Kuznets curve. Economic Modelling, 77, 2-11.

Dutt, K. (2009). Governance, institutions and the environment-income relationship: A cross-country study. Environment, Development and Sustainability, 11, 705-723.

Ehrhardt-Martinez, K., Crenshaw, E. M., \& Jenkins, J. G. (2002). Deforestation and the Environmental Kuznets Curve: A cross-national investigation of intervening mechanisms. Social Science Quarterly, 83(1), 226-243.

Ekperiware, M. C., Olatayo, T. O., \& Egbetokun, A. A. (2017). Human capital and sustainable development in Nigeria: How can economic growth suffice environmental degradation? Economics Discussion Papers, No 2017-29, Kiel Institute for the World Economy.

Eyuboglu, K., \& Uzar, U. (2020). A new perspective to environmental degradation: The linkages between higher education and $\mathrm{CO}_{2}$ emissions. Environmental Science and Pollution Research. https://doi.org/10.1007/s11356020-09414-8

Gangadharan, L., \& Valenzuela, R. (2001). Interrelations between income, health and the environment: Extending the Environmental Kuznets Curve Hypothesis. Ecological Economics, 36(3), 513-531. 
Gill, A. R., Viswanathan, K. K., \& Hassan, S. (2018). The Environmental Kuznets Curve (EKC) and the environmental problem of the day. Renewable and Sustainable Energy Reviews, 81, 1636-1642.

Grossman, G. M., \& Kruger, A. B. (1991). Environmental impacts of the North American Free Trade Agreement. NBER Working Paper, No: 3914.

Grossman, G. M., \& Krueger, A. B. (1995). Economic growth and the environment. Quarterly Journal of Economics, 110 (2), 353-377.

Gui, S., Zhao, L., \& Zhang, Z. (2019). Does municipal solid waste generation in China support the Environmental Kuznets Curve? New evidence from spatial linkage analysis. Waste Management, 84, 310-319.

Hill, R. J., \& Magnani, E. (2002). An exploration of the conceptual and empirical basis of the Environmental Kuznets Curve. Australian Economic Papers, 41(2), 239-254.

Kaika, D., \& Zervas, E. (2013). The environmental Kuznets curve (EKC) theory. Part B: Critical issues. Energy Policy, 62, 1403-1411.

Karlsson, S., \& Löthgren, M. (2000). On the power and interpretation of panel unit root tests. Economic Letters, 66, 249255.

Katircioglu, S., Katircioglu, S., \& Saqib, N. (2020). Does higher education system moderate energy consumption and climate change nexus? Evidence from a small island. Air Quality, Atmosphere \& Health, 13, 153-160.

Kuznets, S. (1955). Economic growth and income inequality. American Economic Review, 45(1), 1-28.

Levin, A., Lin, C., \& Chu, C. J. (2002). Unit root tests in panel data: asymptotic and finite-sample properties. Journal of Econometrics, 108(1), 1-24.

Lind, J. T., \& Mehlum, H. (2010). With or without U? The appropriate test for a u-shaped relationship. Oxford Bulletin of Economics and Statistics, 72(1), 109-118.

Lotz, R. I., \& Morales, L. D. C. (2017). The effect of education on a country's energy consumption: Evidence from developed and developing countries. Economic Research Southern Africa (ERSA) working paper, No: 678.

Mahalik, M. K., Mallick, H., \& Padhan, H. (2021). Do educational levels influence the environmental quality? The role of renewable and nonrenewable energy demand in selected BRICS countries with a new policy perspective. Renewable Energy, 164, 419-432.

Managi, S., \& Jena, P. R. (2008). Environmental productivity and Kuznets Curve in India. Ecological Economics, 65(2), 432-440.

Meadows, D. H., Meadows, D. L., Randers, J., \& Behrens, W. W. (1972). The limits to growth. New York: Universe Books.

Meyer, A. (2015). Does education increase pro-environmental behavior? Evidence from Europe. Ecological Economics, 116, 108-121.

Muttarak, R., \& Chankrajang, T. (2015). Who is concerned about and takes action on climate change? Gender and education divides among Thais. Vienna Yearbook of Population Search, 13, 193-220.

Panayotou, T. (1993). Empirical tests and policy analysis of environmental degradation at different stages of economic development. ILO Technology and Employment Program Working Paper, No: WP238.

Pata, U. C., \& Caglar, A. E. (2020). Investigating the EKC hypothesis with renewable energy consumption, human capital, globalization and trade openness for China: evidence from augmented ardl approach with a structural break. Energy, 119220.

Ponce, P., Alvarado, R., Ponce, K., Alvarado, R., Granada, D., \& Yaguana, K. (2019). Green returns of labor income and human capital: Empirical evidence of the environmental behavior of households in developing countries. Ecological Economics, 160, 105-113.

Rindermann, H. (2007). The g-factor of international cognitive ability comparisons: The Homogeneity of Results in PISA, TIMSS, PIRLS and IQ-Tests Across Nations. European Journal of Personality, 21, 667-706.

Salahodjaev, R. (2018). Is there a link between cognitive abilities and environmental awareness? Cross-national evidence. Environmental Research, 166, 86-90.

Sapkota, P., \& Bastola, U. (2017). Foreign direct investment, income and environmental pollution in developing countries: Panel data analysis of Latin America. Energy Economics, 64, 206-212.

Sarkodie, S. A., Adams, S., Owusu, P. A., Leirvik, T., \& Ozturk, I. (2020). Mitigating degradation and emissions in China: The role of environmental sustainability, human capital and renewable energy. Science of the Total Environment, 719, 137530. 
Shafik, N., \& Bandyopadhyay, S. (1992). Economic growth and environmental quality: Time series and cross-country evidence. Background Paper for World Development Report 1992, World Bank, Washington DC.

Shahbaz, M., \& Sinha, A. (2019). Environmental Kuznets curve for $\mathrm{CO}_{2}$ emissions: A literature survey. Journal of Economic Studies, 46(1), 106-168.

Uddin, M. M. (2014). Causal relationship between education, carbon dioxide $\left(\mathrm{CO}_{2}\right)$ emission and economic growth in Bangladesh. IOSR Journal of Humanities and Social Science, 19(4), 60-67.

Ulucak, R., \& Bilgili, F. (2018). A reinvestigation of EKC model by ecological footprint measurement for high, middle and low income countries. Journal of Cleaner Production, 188, 144-157.

Umaroh, R. (2019). Does education reduce $\mathrm{CO}_{2}$ emmisions? Empirical evidence of the environmental Kuznets curve in Indonesia. Journal of Reviewers on Global Economics, 8, 662-671.

Williamson, C. (2017). Emission, education, and politics: An empirical study of the carbon dioxide and methane environmental Kuznets curve. The Park Place Economist, 25(1), 20-33.

Zafar, M. W., Qin, Q., Malik, M. N., \& Zaidi, S. A. H. (2020). Foreign direct investment and education as determinants of environmental quality: The importance of post Paris Agreement (COP21). Journal of Environmental Management, 270, 1-11. 
Appendix 1. Country List

\begin{tabular}{|c|c|c|}
\hline $\begin{array}{l}\text { Sample } \\
\text { Countries }\end{array}$ & $\begin{array}{c}\text { HDI Rank } \\
\text { (2014) }\end{array}$ & Category \\
\hline Norway & 1 & Very high human development \\
\hline Switzerland & 3 & Very high human development \\
\hline Netherlands & 4 & Very high human development \\
\hline Denmark & 10 & Very high human development \\
\hline Ireland & 11 & Very high human development \\
\hline Sweden & 12 & Very high human development \\
\hline Iceland & 13 & Very high human development \\
\hline $\begin{array}{l}\text { United } \\
\text { Kingdom }\end{array}$ & 14 & Very high human development \\
\hline Korea & 15 & Very high human development \\
\hline Japan & 17 & Very high human development \\
\hline Israel & 19 & Very high human development \\
\hline France & 20 & Very high human development \\
\hline Finland & 24 & Very high human development \\
\hline Italy & 26 & Very high human development \\
\hline Spain & 27 & Very high human development \\
\hline Czech Rep. & 28 & Very high human development \\
\hline Qatar & 31 & Very high human development \\
\hline Cyprus & 32 & Very high human development \\
\hline Estonia & 33 & Very high human development \\
\hline Lithuania & 35 & Very high human development \\
\hline Poland & 35 & Very high human development \\
\hline Slovak Rep. & 37 & Very high human development \\
\hline Chile & 41 & Very high human development \\
\hline Portugal & 41 & Very high human development \\
\hline Hungary & 43 & Very high human development \\
\hline Latvia & 48 & Very high human development \\
\hline Argentina & 49 & Very high human development \\
\hline
\end{tabular}

\begin{tabular}{|c|c|c|}
\hline $\begin{array}{l}\text { Sample } \\
\text { Countries }\end{array}$ & $\begin{array}{c}\text { HDI Rank } \\
(2014)\end{array}$ & Category \\
\hline Bulgaria & 58 & High human development \\
\hline Mauritius & 63 & High human development \\
\hline Mexico & 71 & High human development \\
\hline Iran & 75 & High human development \\
\hline Brazil & 79 & High human development \\
\hline Ukraine & 83 & High human development \\
\hline Armenia & 87 & High human development \\
\hline Thailand & 89 & High human development \\
\hline Tunisia & 90 & High human development \\
\hline Jamaica & 96 & High human development \\
\hline Colombia & 98 & High human development \\
\hline Moldova & 114 & Medium human development \\
\hline El Salvador & 115 & Medium human development \\
\hline Kyrgyz Rep. & 125 & Medium human development \\
\hline Tajikistan & 133 & Medium human development \\
\hline Lao PDR & 139 & Medium human development \\
\hline Nepal & 145 & Low human development \\
\hline Madagascar & 155 & Low human development \\
\hline Senegal & 163 & Low human development \\
\hline Benin & 165 & Low human development \\
\hline
\end{tabular}

Appendix 2. Test Results

\begin{tabular}{llr}
\hline Hausman test FEM vs REM & $\chi^{2}(5)$ & $34.12^{*}$ \\
Modified Wald test & Prob $>\chi 2$ & 0.0000 \\
Pesaran's CSI test & $\chi 2(47)$ & $20434.13^{*}$ \\
Baltagi-Wu LBI & Prob $>\chi 2$ & 0.0000 \\
& & $6.644^{*}$ \\
Modified Bhargava et al. Durbin Watson & & $0.80257607^{*}$ \\
\hline Coefficients with $\left({ }^{*}\right)$ are significant at 1\%. & $0.50093401^{*}$ \\
\hline
\end{tabular}


This Page Intentionally Left Blank 